\title{
Analysis of How Sex Education in Asia is Expressed in the Media
}

\author{
Chenlinyang Wang
}

\author{
St.Anthony's high school \\ 275 Wolf Hill Road, South Huntington, NY 11747 \\ Corresponding author.Email: Chenlinyang.wang2022@stanthonyshs.org
}

\begin{abstract}
The influence of media on sex education in Asia is of great significance in modern society of Asia. So, the paper analyzes how sex education in Asia is expressed in the media. This paper carries out research and analysis from the following aspects: how sex education in Asia is affected by the media; why is the situation only exists in Asia; how the traditional culture and ideas in Asia are integrated with the media. Through various data surveys and the support of previous research cases, this paper finds that Asian media is missing in terms of sex education. Because of the influence of customs and local traditional culture, Asian media will be more cautious and even avoid talking about it when reporting some news about sex education. The wrong way of publicity leads to the lack of sex knowledge of teenagers and produces great gender discrimination. At the same time, it also increases the incidence of diseases. It is necessary to strengthen the popularization of sexual knowledge in public activities and should not publicize sex education as a disgrace and change the way of media publicity. The society should lift veil of sex education and expand it through the media spread.
\end{abstract}

Keywords: Sex education, Asian, teenager, media, Asian culture, gender stereotypes

\section{INTRODUCTION}

Whether sex education should be carried out in Asia has always been a controversial topic. Under the influence of Asian cultural background, most Asians regard it as an unspeakable secret. For example, subject to the influence of traditional feudal thoughts, China's sex education started relatively late. In the early years, no matter between teachers and students or between parents and children, the topic of "sex" was always deliberately avoided. As a result, the Chinese educational environment, which was advanced in all aspects, was short of "sex education". After the introduction of the new Law on the Protection of Minors, the last weak board will be filled for the wooden barrel effect of education. In recent years, the gap in educational resources between the East and the West is getting smaller and smaller. When it comes to sex education, it is still in the Java era, while foreign countries have already popularized $5 \mathrm{G}$. There is not much research on this topic in the academic community, so the author aims to analyze the state and role of the media in the process of sex education in Asia. The specific problems to be studied in this paper are: the current situation of sex education in Asia; the specific manifestations of media in sex education in Asia; how to improve this problem. The paper can provide theoretical basis and reference for the future media's dissemination of sex education in Asia and related research. At the same time, it can also make the society pays more attention to the importance of family sex education and social sex education, which is conducive to the development of children's mental health. It helps to strive to realize the ideal of equal and open sex education, realize gender equality, advocate individual rights and respect multiple choices.

\section{SEX EDUCATION IN ASIA}

Under the influence of Asia's unique cultural background, sex education in Asia is actually lacking. Family avoidance, media restrictions and loopholes in education have led to great discrimination against sex education in Asia, which will greatly affect the balanced and stable social development of mankind in the future. There is gender inequality between men and women. Some people think they are shameful because of some physiological reactions. For example, women think they are dirty during menstruation. Families prefer boys and 
think that only boys can inherit the genealogy. Facing modern diversified society, some teenagers will do a lot of unexpected things out of curiosity and increase the probability of diseases, such as HIV, eclampsia, postpartum endometritis and a series of problems [1].

\section{1 the definition of sex education}

Sex education is a kind of education. It aims to help people gain the information, skills and motivation to make healthy decisions about sex and sexuality. It includes human development, relationships, personal skills, sexuality, sexual health and society and culture [2].

\section{2 the sex education status in Asia}

In Asian families, mothers often teach their daughters and fathers teach their sons, which is still the traditional way of education. When the children ask where they are from, Asian parents usually say, "I happened to pass by a garbage can and heard a child crying inside, so I brought you home" or "I paid for you" and a series of evasive answers.

Instead of facing the problem directly, they give children more outrageous answers, which leads to children being implicitly misled from an early age. But when the child is in adolescence and knows a little, they know their parents are lying to them. But they do not know exactly what kind of situation. Why parents want to hide? How the hell did I get here? In this case, children will be more curious about it, which is more likely to cause the occurrence of danger.

The female students in junior middle school sneak to the bathroom for a few days every month and hide a mysterious thing in their sleeves or pockets. What they cover-up is nothing else. They are sanitary napkins. Because they think it should not be on the table. People inevitably have some pronouns to describe things they think can't be on the table, of course, such as sanitary napkins or menstruation. After data investigation, it was found that people had created many different names for it long ago, such as "Laishier", "bigger aunt", "lijia" and other nouns to replace it. People in some places even think that women are not holy during menstruation.

\section{MEDIA}

\section{1 the definition in media}

Media is the means of communication, as radio and television, newspapers, magazines, and the internet, that reach or influence people widely [3]. Media is usually divided into five categories. Print media includes newspapers and magazines. Broadcast media contains $\mathrm{TV}$, and radio. And media outside of home and the Internet [4]. Among them, the Internet is the fastest and most convenient way to spread, and it is the most frequently used way in today's modern society.

\section{2 how sex education in Asia is affected by the media}

\subsection{1 the India}

In India, when women have menstruation, they need to leave home and live in the forest outside. The film Padman [5] (as shown in figure 1) tells the story very well. Rahimi was upset to see his wife using a dirty cloth while menstruating, but she told him to leave the women alone. Undaunted, Rahimi bought his wife expensive sanitary pads. When she saw these pads, she refused to use them and said that Rahimi humiliated her. The words are as shown below, that is, "We woman.......would rather die for illness than live in shame".

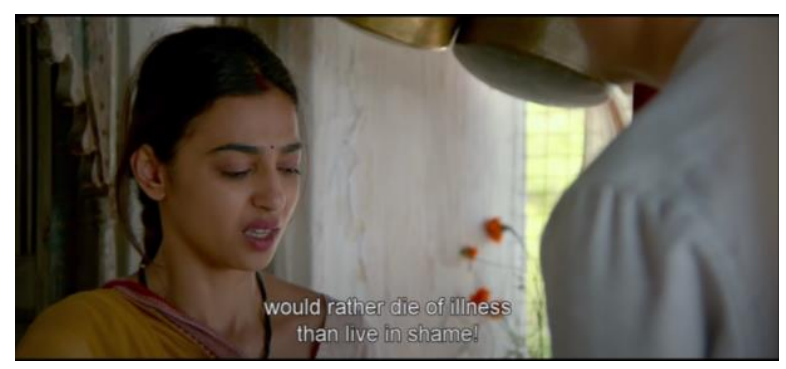

Figure 1 Padman

At that time, media was not widely available in India, even women can be sexist about themselves. In In Asia regions, the probability of partner abuse is high as shown in figure 2. Unfortunately, the film is adapted from the true experience of Arunachalam Muruganantham [6], a social activist in Tamil Nadu. Rose George [7], a columnist on women's issues, once dealt with adolescent girls in rural India and Pakistan and wrote a book about taboos and euphemisms. A considerable number of regions in the world regard menstruation as taboo and are ashamed to talk about it. Therefore, many girls do not get enough health resources and even psychological support and help [8].

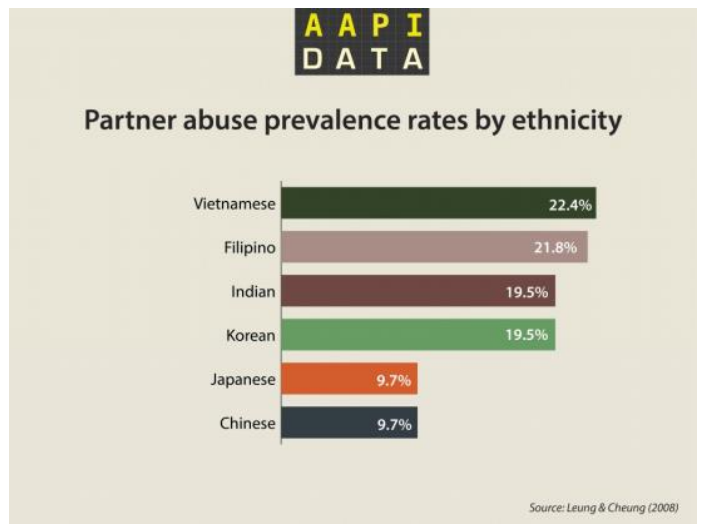

Figure 2 Partner abuse prevalence rates by ethnicity in Asia 
In India, $73 \%$ of girls have never had a female relative tell them about menstruation before their first menstruation. Due to the influence of cultural background, there is less publicity on sex education. However, people often see news about rape in a certain area, or where teenage pregnancy occurs. But people have never seen relevant reports that teach them how to protect themselves from similar things.

At this time, many people will look at this with colored glasses. They will only criticize the participants in the event and carry out personal attacks on the people in the event.They have not thought about what is the reason for the occurrence of this event and what kind of background led to the occurrence of this event.

\subsection{2 other regions of Asia}

In other regions of Asia, $62 \%$ of children are victims of psychological, physical, and sexual abuse. Using stricter criteria, child abuse occurs in 6\%. Most abusers are male relatives. The psychological patterns of abusers cannot be determined, although risk factors in families where abuse occurs can be determined. Children in distress due to sexual abuse do not usually report it, but the distress can be recognized because of hints and changes in the child's behavior [9].

When children were young, they didn't have an obvious definition of "sexual assault". Children as young as four can become victims [10]. They couldn't tell whether they were violated or not. Some of them would regard "aggression" as adult love and care.

In one case (EF1), the activity (i.e."playing PlayStation") was used as a pretext to approach the victim by the offender. He would tell the boy that he was only allowed to play if he had sexual relations with him [11]. Sexual violence is not just about violence, it's about bribery, love, and seduction.

A four-year-old child doesn't know or understand what he's going through. Some can't even speak clearly at the age of four, and will have a shadow for the rest of his life. A review of 217 studies found that one in eight children (12.7 per cent) worldwide [9] were sexually assaulted before the age of 18 . One in 20 girls aged 15 to 19 , or 13 million, has been sexually abused and exploited [12].

The famous case was the Cho Doo-soon Case. The morning of 11 December, an eight-year-old girl was walking to school in Ansan, south-west Seoul, when she was kidnapped by Cho Doo-soon, a 56-year-old exconvict. He took her to a toilet in a nearby church where he brutally beat and raped her [13]. Parents should not lack sex education for their children because their children are still young. Younger children often don't know how to protect themselves. Like the kid in this case, she was just going to school as usual, but she was so badly hurt, physically and psychologically.

\section{SOLUTIONS}

\subsection{Expanding media communication channels}

Media communication is one of the fastest and simplest ways to influence human thought. Although many movies are promoting the sexual assault of children, such as the movie Silenced and the famous book Fang Siqi's First Love Paradise, only these aspects of publicity are incomplete.

There are many ways for the media to spread sex education. Increasing the shooting of TV variety shows is a good way to spread sex education. Some famous celebrities can be invited to tell people that sex education is not an unspeakable secret by telling their own experiences/stories. It is also possible to set up a psychological story radio station to gather all the people to participate anonymously, and to gather the public to tell their own stories through the host instead of reading or making phone calls, so that everyone knows that sex education should not be avoided. There are even public funds to help hurt children/adults recover.

\subsection{Strengthening family sex education}

The cultural prejudice of sex education in Asia can be broken more quickly and better by using diversified media communication. Considering some children age is small, and can't understand what the media expresses, the parents can draw simple picture books or children's songs and animation to tell children some important parts to realize and protect themselves, and realize that no matter what gender, all people are equal.

Don't feel inferior because you are different from others. Also parents cannot ignore the boy's sexual education at the same time. In the child victims, about $6 \%$ of abuse as a boy. When it is necessary for parents to control their children properly, if there are exceptions, they can give more care to their children as soon as possible. Since childhood gradually affects children, parents should let the children know that their body is precious. People need sex education because it can be violated at any age.

\subsection{Other effective attempts}

While adding TV programs and how to protect their knowledge columns, some news websites can also add some public service advertisements or posters to promote them. Everyone should realize that this is not a very shameful thing, but a weapon to protect them. The society should vigorously promote gender equality and make people realize that they should not think they are unclean and ashamed because of some of their 
physiological reactions. At the same time, some variety shows can be held and some celebrities can be invited to talk about their experience to increase people's tolerance.

\section{CONCLUSION}

According to the results of the study, Asia's sex education under Asian culture background is missing. The media needs to reflect the authenticity of news reports. It should show the positive role of social media in sex education and publicity, so that the whole society and family can face the importance and necessity of sex education. Of course, there are limitations in analyzing only few regions of Asia. When analyzing only a few countries such as India and South Korea, the information is not comprehensive. But in the future, it is an indisputable consensus that teenagers need sex education. In this article, more theoretical cases from films or book are used. In the future work, the author will participate in the investigation and add more actual cases to conduct more data level analysis.

\section{REFERENCES}

[1] World Health Organization. (n.d.). Adolescent pregnancy. World Health Organization. Retrieved November 29, 2021, from https://www.who.int/news-room/factsheets/detail/adolescent-pregnancy.

[2] Parenthood, P. (n.d.). What is sex education? Planned Parenthood. Retrieved November 29, 2021, from https://www.plannedparenthood.org/learn/foreducators/what-sex-education

[3] Dictionary.com. (n.d.). Media Definition \& meaning. Dictionary.com. Retrieved November 29, 2021, from https://www.dictionary.com/browse/media.

[4] Bbamantra. (2017, October 23). Media - types of media, print, broadcast, outdoor, internet - BBA: Mantra. BBA. Retrieved November 29, 2021, from https://bbamantra.com/media-types-characteristics/.

[5] Sony Pictures Releasing. (2018). Padman. India. Retrieved November 24, 2021, from https://www.netflix.com/title/81016191? source=35 .

[6] Arunachalam Muruganantham, a social entrepreneur who created the machine for making affordable sanitary towels

[7] Rose George is a British author and journalist. Her books are Nine Pints, about blood. Ninety Percent of Everything, about shipping

[8] George, R. (2019). Nine pints. Granta Books. Macmillan Publishing Services, pp.1-2.

[9] A, H.-L. M. M. S. S. (n.d.). [sexual abuse in children: Determination, identification, and interventions].
Harefuah. Retrieved November 26, 2021, from https://pubmed.ncbi.nlm.nih.gov/8846952/.

[10] BBC. (2000, September 15). BBC Chinese $|\mathrm{x}| \mathrm{x} \square$. BBC News. Retrieved November 26, 2021, from http://news.bbc.co.uk/chinese/simp/hi/newsid_920 000/newsid_926900/926913.stm.

[11] Child abuse \& neglect - nationalcac.org. (n.d.). Retrieved November 27, 2021, from https://www.nationalcac.org/wp content/uploads/2019/05/A-boy-being-a-victimnobody-really-buys-that-you-know.pdf.

[12] Action to eliminate sexual abuse and exploitation of children- unicef.org. (n.d.). Retrieved November 29, 2021, from https://www.unicef.org/media/102371/file/CSAESummary-Chinese.pdf.

[13] BBC. (n.d.). Controversy over the Korean judicial system caused by the release of sex offender Zhao Douchun in the Suyuan case. BBC News Chinese Retrieved November 27, 2021, from https://www.bbc.com/zhongwen/simp/world55543271. 